well as single stranded natural RNAs as templates for DNA synthesis. And, rubbing home the message, Cavalieri and Carroll reported two weeks ago in Nature $(232,254 ; 1971)$ that the addition of traces of calf thymus DNA to $E$. coli ribosomal RNA resulted in a three to ten-fold increase in the incorporation of the four deoxynucleoside triphosphates catalysed by $E$. coli DNA polymerase. This result is, of course, entirely reminiscent of the stimulatory effect of Goulian pieces on DNA synthesis catalysed by DNA polymerase I with natural DNA templates.

Mindful of these findings, it is perhaps rash of Werner et al. (Biochem. Biophys. Res. Comm., 44, 433; 1971), who have found that skin cells from people with xeroderma pigmentosum contain an enzymatic activity, which uses poly rG.dC as a template for DNA synthesis, that is absent from normal human skin cells, to conclude that xeroderma pigmentosum skin cells are infected with a tumour virus and contain a reverse transcriptase. In the light of Cavalieri's experiments and Spiegelman's cautionings one can offer an equally plausible alternative explanation of the data Werner et al. present.

There can be no questioning the fact that xeroderma pigmentosum cells lack some if not all DNA repair mechanisms and fail to excise pyrimidine dimers. Moreover this defect may well be responsible for the greatly enhanced incidence of skin carcinomas among people with xeroderma pigmentosum. Perhaps the different responses to poly rG.dC and native DNA of extracts of normal and xeroderma pigmentosum cells, which Werner et al. have detected, are the result of a mutation which has changed the template specificity of the cell's DNA repair enzyme(s). If human DNA repair enzymes resemble $E$. coli DNA polymerase I they will no doubt be induced to use, in the highly artificial environments set up by biochemists, synthetic RNAs and DNA/ RNA hybrids as template. It does not take much stretching of the imagination to picture a mutation which would cause such an enzyme to use RNAs and hybrids in such experimental conditions in preference to native DNA, and at the same time impair DNA repair in vivo.

\section{CONSERVATION}

\section{Rhinos Survive}

from a South African Correspondent DURING the early history of South Africa at least two big game species, the true quagga, Equus quagga, and the bluebuck, Hippotragus leucoph- aeus, were exterminated and many other species were severely curtailed in numbers and distribution. The approach to these matters has now improved considerably, however, as is shown by two recent reports.

One report by Dr U. de V. Pienaar, Nature Conservator of the Kruger National Park, points out (Koedoe, 13, $157 ; 1970)$ that the southern white (or squarelipped) rhinoceros, Ceratotherium simum, is now safely re-established in the park after having been extinct in the eastern Transvaal for 65 years. The last white rhino in this area was apparently shot around 1896, when it seemed to be heading for extinction throughout its range. But it survived in the Umfolozi-Hluhluwe corridor complex in Zululand and gradually recovered so well that a danger arose of over-utilization and destruction of the available habitat. As long ago as 1928 the possibility of translocating rhino from Zululand to other parts of their former range was suggested by the naturalist Herbert Lang, but it was not until about 1960 that it became feasible for the Natal Parks Board to undertake large scale translocation. Even so, more than 1,200 animals remain in the UmfoloziHluhluwe corridor complex, so that the threat of over-utilization of the habitat has not been averted

The second report, by $\mathrm{Dr} \mathrm{W}$. von
Richter of the Mammal Research Unit, University of Pretoria (Ann. Transv. Mus., 27, 35 ; 1971), discusses the present status of the black wildebeest, Connochaetes gnou. This animal originally occurred extensively in the central open plains of South Africa, particularly the highveld grasslands of the southern Transvaal, Orange Free State and Karoo and the central and southern Cape grassveld. In addition it was probably a seasonal migrant into Natal. Within its range it was initially extremely abundant, but indiscriminate hunting, together with periodic disease outbreaks and gradual curtailment of the habitat to make way for human settlement, caused it to dwindle to about 600 animals, chiefly in the Orange Free State and southern Transvaal, by the turn of the century. Since then, however, numbers have increased steadily to more than 1,000 in 1945 , about 1,800 in 1965 and 3,100 in 1970 , as well as more than 155 animals living in zoological gardens in various parts of the world. The most marked increase has been in the Transvaal.

Von Richter concludes that, whereas it was thanks to the initiative of a few farmers that the black wildebeest was saved from extinction, an important factor in its survival has been the establishment of breeding herds in the national parks and provincial reserves.

\title{
Structure and Base Composition in DNA
}

IN the next issue of Nature New Biology, Bram contradicts the crystallographic dictum that DNA conformation is essentially independent of base composition. From X-ray scattering envelopes on gels or concentrated solutions, Bram previously found that the conformation of a DNA of typical base composition was little different from the B-structure found in fibres at high humidity. The same was true for DNA within calf thymus nucleohistone. A comparison of observed with calculated scattering curves indicated a small difference in the helix twist from that of B-DNA. Bram has now examined two bacterial DNA species containing 67 and 69 per cent of $(A+T)$, as well as the alternating polymer, poly $\mathrm{d}(\mathrm{AT})$, and he reports that these do not fit the same model. The axial radius of gyration is similar, but the cross-section of the AT-rich species has much greater anisotropy. The curves fit neither a B nor an A nor a C-type of model, but all that can be said about the geometry of the new structure at the present stage is that the helix pitch is some 10 per cent larger than that of DNA of lower AT content. Bram suggests that the difference may be in the pucker of the sugar ring.
Bram notes that the transition of the DNA structure between the two forms is highly cooperative, in the sense that a large structural difference is observed between molecules containing 56 per cent and 67 per cent $(A+T)$, but as between 56 per cent and 28 per cent $(\mathrm{A}+\mathrm{T})$ there is no further detectable change. Whether this apparent disagreement with earlier X-ray diffraction studies on fibres is a result of inadequate diffraction data on high-AT species, or on differences between the fibre and solution tates, remains to be established.

The biological implications of the findings that Bram reports may well be profound. If, as he suggests, AT-rich regions in a single chain cause alternation between the two types of structure, this offers a basis for a whole series of protein recognition processes. Some enzymes, repressors, and such molecules as polylysine, all show a strong binding preference for DNA species rich in (A+ T). In bacterial DNAs tracts extremely rich in $(A+T)$ have in fact been found. The observations would also make necessary a re-examination of the dependence of spectroscopic and other properties of DNA on the base-composition. The possibility exists that a similar effect may occur in RNA. 